\title{
In-hospital outcomes with anterior versus posterior approaches in total hip arthroplasty: meta-analysis of randomized controlled trials
}

This article was published in the following Dove Press journal: Journal of Pain Research

\author{
Larry E Miller' \\ Atul F Kamath ${ }^{2}$ \\ Friedrich Boettner ${ }^{3}$ \\ Samir K Bhattacharyya ${ }^{4}$ \\ 'Miller Scientific Consulting, Inc., \\ Asheville, NC, USA; ${ }^{2}$ Penn Medicine, \\ Department of Orthopedic Surgery, \\ Leonard Davis Institute of Health \\ Economics, Philadelphia, PA, USA; \\ ${ }^{3}$ Hospital for Special Surgery, New \\ York, NY, USA; ' ${ }^{4}$ ePuy Synthes, \\ Raynham, MA, USA
}

\begin{abstract}
Purpose: The purpose of this study was to determine whether in-hospital outcomes are different with anterior approach (AA) or posterior approach (PA) in primary total hip arthroplasty (THA). Methods: We performed a systematic review with random-effects meta-analysis of randomized controlled trials (RCTs) comparing AA with PA in primary THA. Hospital outcomes were reported as odds ratio (OR), weight mean difference, or standardized mean difference (SMD). Results: A total of seven RCTs with 609 patients were included. Outcomes favoring AA included $1.4 \mathrm{~cm}$ shorter incision $(p=0.045), 0.5$ days shorter hospital stay $(p=0.01), 0.5$ points less pain on a $0-10$ scale $(p=0.007)$, and less opioid use ( $\mathrm{SMD}=-0.39$ corresponding to 12 fewer morphine equivalents per day, $p=0.01$ ). The procedure time was 16 minutes longer with AA vs. PA $(p=0.002)$. There were no statistical differences between AA and PA in operative blood loss (mean difference $=19 \mathrm{~mL}, p=0.71)$, transfusions $(9.7 \%$ vs. $16.2 \%, \mathrm{OR}=0.45, p=0.39)$, or complications $(5.5 \%$ vs. $4.1 \%, \mathrm{OR}=1.42, p=0.62)$.

Conclusion: While the AA to primary THA may take longer time compared with the PA, the incision is shorter, and patients report slightly less pain, require less opioid medication, and leave the hospital earlier. The clinical relevance of these differences during longer-term follow-up is uncertain. The choice of surgical approach in primary THA should also consider factors such as experience of the surgeon and preferences of the surgeon and patient.
\end{abstract}

Keywords: complications, opioid, pain, systematic review, THA

\section{Introduction}

Hip osteoarthritis is a degenerative joint disease that causes progressive damage to articular cartilage and surrounding structures and is a common cause of pain and disability among older adults. The incidence of symptomatic hip osteoarthritis has been estimated at 1.3/100 person-years in adults aged 45 years or older. ${ }^{1}$ In individuals with debilitating osteoarthritis-related symptoms that are unresponsive to conservative measures, total hip arthroplasty (THA) may be indicated, which is arguably the most clinically and cost-effective orthopedic surgery. ${ }^{2}$ The demand for THA is expected to increase to a projected number of 572,000 annual procedures in the USA by $2030 .^{3}$

Various surgical approaches for primary THA have been utilized including anterior, anterolateral, direct lateral, and posterior/posterolateral. In recent years, the anterior approach (AA) has been increasingly advocated as a muscle-sparing approach to THA with purported advantages of lower perioperative pain, faster functional recovery, and lower dislocation risk compared with a standard posterior approach (PA). ${ }^{4}$ The benefits of the AA may be attributable to a short incision that utilizes the intermuscular and
Miller Scientific Consulting, Inc., 1854

Hendersonville Road, No 23I, Asheville, NC 28803, USA

Tel +l 8284501895

Email larry@millerscientific.com 
internervous intervals between the sartorius and the tensor fascia lata muscles, with no detachment of muscles or tendons. In contrast, the standard PA utilizes a longer incision and requires significant disturbance of the hip capsule, splitting of the gluteus maximus, and detachment of the external rotators. Some have argued that the benefits of AA were realized due to factors unrelated to surgical approach such as patient selection and postoperative rehabilitation protocols. ${ }^{5}$ Data from high-quality studies are lacking to strongly recommend one approach over the other. Current evidence regarding comparative efficacy of different surgical approaches for primary THA has been mainly derived from case series and nonrandomized comparative studies. Consequently, systematic reviews on the topic have generally relied on these lower-quality studies to develop recommendations. ${ }^{6-8}$ Randomized controlled trials (RCTs) remain the gold standard for assessing medical interventions because their design controls both measured and unmeasured confounding variables. To date, no systematic review with direct-evidence meta-analysis of RCTs comparing the AA with the PA in primary THA has been performed. The purpose of this systematic review and direct-evidence meta-analysis of RCTs was to compare in-hospital procedural and recovery data with the AA or PA in primary THA.

\section{Methods}

\section{Literature search}

This study was performed according to the preferred reporting items for systematic reviews and meta-analyses (PRISMA). ${ }^{9}$ We searched MEDLINE and Embase for RCTs on the effects of primary THA with an AA versus PA. We used combination searches that included therapy-specific keywords such as THA and total hip arthroplasty and surgical approach-specific keywords such as anterior, direct, posterior, posterolateral, and Smith-Peterson with publication type denoted as Randomized Controlled Trial or MeSH Term denoted as Prospective Studies. Additionally, manual searches were conducted using the Directory of Open Access Journals (DOAJ), Google Scholar, and the reference lists of included papers and relevant meta-analyses. No date or language restrictions were applied to the searches. Articles published in non-English journals were translated into English. The final search was conducted on June 30, 2017.

\section{Study selection}

Two researchers independently selected studies for inclusion in the review. Disagreements were resolved by consensus. Eligible studies were RCTs of AA vs. PA in primary THA where the predominant diagnosis was osteoarthritis. Titles and abstracts were initially screened to exclude review articles, commentaries, letters, case reports, and obvious irrelevant studies. Full texts of the remaining articles were retrieved and reviewed. Studies were excluded if all patients received bilateral THA or revision THA or if main outcomes were not reported or calculable.

\section{Data extraction}

An initial database was developed, pilot tested, and refined to ensure consistency with outcomes reported in the literature. Data were independently extracted from eligible peer-reviewed articles by two researchers. Data extraction discrepancies were resolved by consensus. The types of data recorded in the standardized data extraction forms included general manuscript information, study design, patient characteristics, study characteristics, risk of bias, and outcome data.

\section{Definitions and outcomes}

This review included outcomes reported from surgery to hospital discharge. The main outcomes included incision length, procedure time, procedural blood loss, blood transfusion, opioid use, pain severity, length of hospital stay, and complications. Incision length $(\mathrm{cm})$, procedure time ( $\mathrm{min})$, procedural blood loss (mL), blood transfusions (yes/no), and length of hospital stay (days) were reported identically in all studies. Postoperative pain severity was reported using a $0-10$ visual analog scale. Opioid use was reported as morphine milligram equivalents required during hospitalization. Complications included any reported complication occurring during surgery until the time of hospital discharge. The Cochrane Collaboration tool was used for assessing risk of bias in RCTs. ${ }^{10}$ The risk of bias tool assessed sequence generation, allocation concealment, blinding, incomplete outcome data, selective outcome reporting, and other sources of bias. For each study, each element was rated as low, uncertain, or high bias risk.

\section{Data synthesis}

Outcomes reported on a common scale among studies were reported as the weighted mean difference using the original units of measure. Risk of blood transfusion and hospital complications were reported as the event rate in each group and the odds ratio (OR) for group comparisons. Opioid use was reported using the standardized mean difference (SMD) since morphine equivalents were reported over different periods during hospitalization. SMD values of $0.2,0.5,0.8$, and 1.0 were defined as small, medium, large, and very large effect sizes, respectively. ${ }^{11}$ For each outcome, the effect size 
and $95 \%$ confidence intervals (CIs) were calculated in each study and visually displayed using forest plots. We used the $I^{2}$ statistic to estimate heterogeneity of treatment effects with values of $\leq 25 \%, 50 \%$, and $\geq 75 \%$ representing low, moderate, and high inconsistency, respectively. ${ }^{12} \mathrm{~A}$ fixed-effect model was used for meta-analysis when there was no significant heterogeneity $\left(I^{2}<50 \%\right)$; otherwise, a random-effect model was used. We planned to conduct subgroup analyses to explore sources of heterogeneity for outcomes reported in at least 10 studies. $p$-values were two sided with a significance level $<0.05$. All analyses were performed using Comprehensive Meta-Analysis (version 3.3; Biostat, Englewood, NJ, USA).

\section{Results}

\section{Study selection}

After screening 323 records for eligibility, 7 RCTs with 609 patients were included in the meta-analysis. ${ }^{13-19}$ One RCT was excluded due to lack of main outcome reporting. ${ }^{20}$ The most common reason for exclusion was nonrandomized study design. A flow diagram of study identification and selection is shown in Figure 1.

\section{Patient and study characteristics}

Mean patient age ranged from 61 to 65 years (median $=63$ years), female enrollment ranged from $45 \%$ to $63 \%$ ( median $=55 \%$ ), and mean body mass index (BMI) ranged from 23 to $31 \mathrm{~kg} / \mathrm{m}^{2}$ (median $\left.=28 \mathrm{~kg} / \mathrm{m}^{2}\right)$ among studies. No study clearly included learning curve cases (Table 1). Risk of bias assessment for each study is described in Table 2. In general, reporting of randomization methods and treatment allocation was poor and associated with uncertain bias risk. No study blinded patients, surgeons, or assessors of outcomes reported in this meta-analysis. Given that this meta-analysis consists of objective and patient-reported outcomes, the risk of bias associated with unblinded studies was uncertain overall. All AA procedures utilized a direct AA, and all PA procedures utilized a standard posterolateral approach with gluteal muscle splitting technique.

\section{Hospital outcomes}

Outcomes favoring AA included $1.4 \mathrm{~cm}$ shorter incision $(p=0.045)$ among 5 studies (Figure 2), ${ }^{13,14,16,18,19} 0.5$ days shorter hospital stay $(p=0.01)$ among 5 studies (Figure 3$),{ }^{13-}$ ${ }^{15,18,19} 0.5$ points less pain on a $0-10$ scale $(p=0.007)$ among 2 studies (Figure 4), ${ }^{13,19}$ and less opioid use (SMD $=-0.39$ corresponding to 12 fewer morphine milligram equivalents per day, $p=0.01$ ) among 2 studies (Figure 5). ${ }^{13,14}$ Procedure time was 16 minutes longer with AA vs. PA $(p=0.002)$ among 5 studies (Figure 6). ${ }^{13,14,16,18,19}$ There were no statistical differences between $\mathrm{AA}$ and PA in operative blood loss (mean difference $=19 \mathrm{~mL}, p=0.71$ ) among 4 studies (Figure 7), ${ }^{13,16,18,19}$ blood transfusions (9.7\% vs. $16.2 \%$, $\mathrm{OR}=0.45, p=0.39$ ) among 4 studies (Figure 8$),{ }^{14,16,18,19}$ or hospital complications $(5.5 \%$ vs. $4.1 \%, \mathrm{OR}=1.42, p=0.62)$

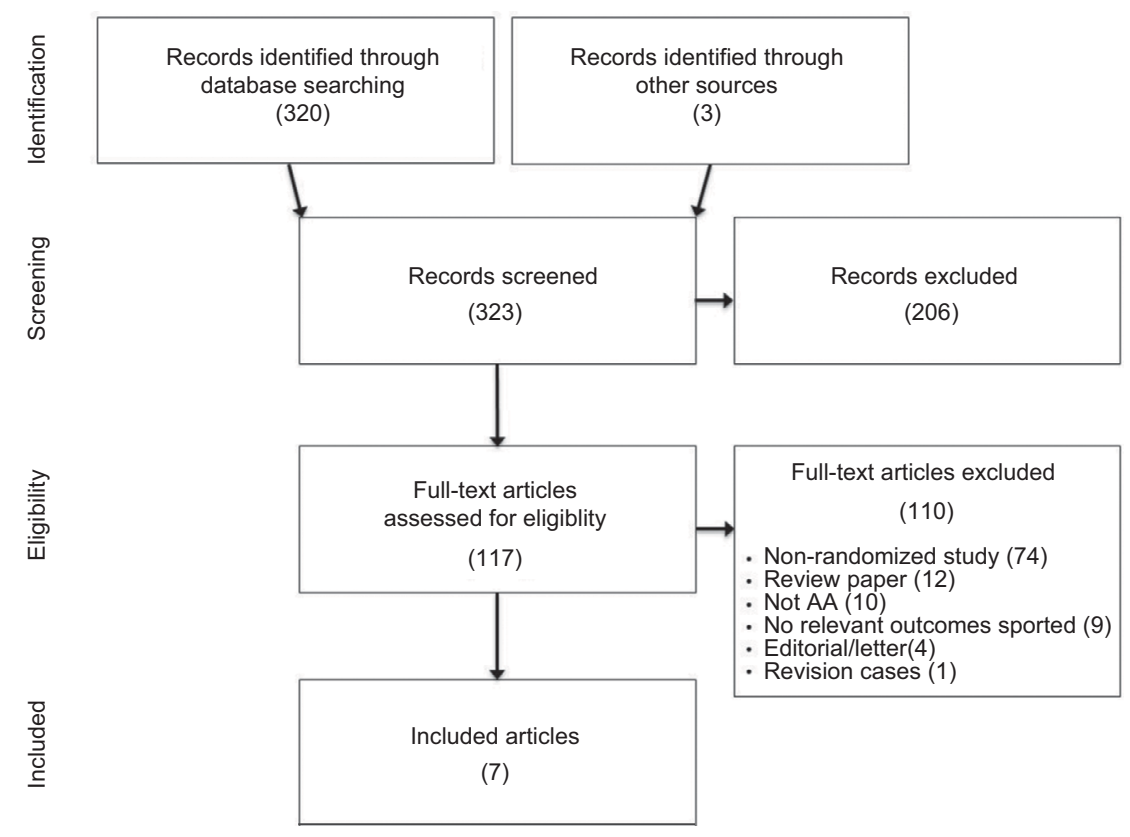

Figure I PRISMA study flow diagram.

Abbreviations: PRISMA, preferred reporting items for systematic reviews and meta-analyses; AA, anterior approach. 
Table I Patient characteristics and surgical details

\begin{tabular}{|c|c|c|c|c|c|}
\hline Study & n, AA:PA ${ }^{a}$ & $\begin{array}{l}\text { Age (years), } \\
\text { AA:PA }\end{array}$ & $\begin{array}{l}\text { Female (\%), } \\
\text { AA:PA }\end{array}$ & $\begin{array}{l}\text { BMI }\left(\mathrm{kg} / \mathrm{m}^{2}\right) \text {, } \\
\text { AA:PA }\end{array}$ & $\begin{array}{l}\text { Learning cases } \\
\text { included }\end{array}$ \\
\hline Barrett et al ${ }^{13}$ & $43: 44$ & $61 \pm 9: 63 \pm 8$ & $33: 57$ & $3 I \pm 5: 29 \pm 5$ & No \\
\hline Cheng et al ${ }^{14}$ & $35: 38$ & $59 \pm 11: 63 \pm 10$ & $57: 53$ & $28 \pm 3: 28 \pm 5$ & No \\
\hline Christensen and Jacobs ${ }^{15}$ & $28: 23$ & $64 \pm 9: 65 \pm 9$ & $54: 52$ & $31 \pm 5: 30 \pm 4$ & No \\
\hline Luo et $\mathrm{al}^{16}$ & $52: 52$ & $62 \pm 7: 64 \pm 7$ & $67: 58$ & $23 \pm 4: 24 \pm 4$ & No \\
\hline Taunton et al ${ }^{17}$ & $27: 27$ & $62: 66^{c}$ & $56: 52$ & $28: 29^{c}$ & No \\
\hline Zhang et al ${ }^{18}$ & $60: 60$ & $61: 63^{c}$ & $58: 53$ & $-^{\mathrm{d}}$ & Not specified \\
\hline Zhao et al ${ }^{19}$ & $60: 60$ & $65 \pm 12: 62 \pm 15$ & $60: 56$ & $24 \pm 3: 26 \pm 3$ & No \\
\hline
\end{tabular}

Notes: ${ }^{a}$ Reported as number of patients or hips. ${ }^{b}$ Data reported as mean $\pm \mathrm{SD}$. cMeasures of variability about the mean not reported. ${ }^{\mathrm{d} A l l}$ patients with $\mathrm{BMI}<27 \mathrm{~kg} / \mathrm{m}^{2}$. Abbreviations: AA, anterior approach; BMI, body mass index; PA, posterior approach.

Table 2 Cochrane risk of bias assessment

\begin{tabular}{|c|c|c|c|c|c|c|c|}
\hline Study & $\begin{array}{l}\text { Random } \\
\text { sequence } \\
\text { generation }\end{array}$ & $\begin{array}{l}\text { Allocation } \\
\text { concealment }\end{array}$ & $\begin{array}{l}\text { Blinding of } \\
\text { participants }\end{array}$ & $\begin{array}{l}\text { Blinding of } \\
\text { personnel }\end{array}$ & $\begin{array}{l}\text { Blinding of } \\
\text { outcome } \\
\text { assessment }\end{array}$ & $\begin{array}{l}\text { Incomplete } \\
\text { outcome } \\
\text { data }\end{array}$ & $\begin{array}{l}\text { Selective } \\
\text { outcome } \\
\text { reporting }\end{array}$ \\
\hline Barrett et $\mathrm{al}^{13}$ & $\square$ & 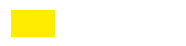 & $\square$ & $\square$ & $\square$ & $\square$ & $\square$ \\
\hline Cheng et al ${ }^{14}$ & 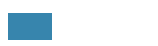 & 口 & 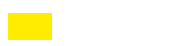 & 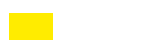 & 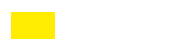 & 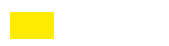 & Z \\
\hline Christensen and Jacobs ${ }^{15}$ & 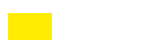 & $\square$ & 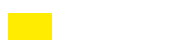 & 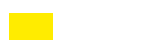 & 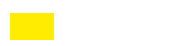 & $\square$ & $\square$ \\
\hline Luo et $\mathrm{al}^{16}$ & 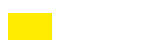 & 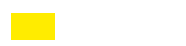 & $\square$ & $\square$ & $\square$ & $\square$ & 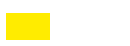 \\
\hline Taunton et al ${ }^{17}$ & 口 & 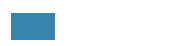 & 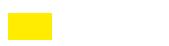 & 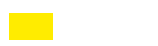 & 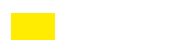 & 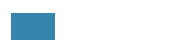 & 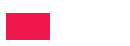 \\
\hline Zhang et al ${ }^{18}$ & 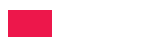 & 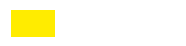 & 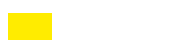 & 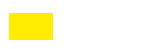 & 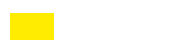 & 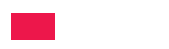 & 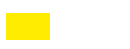 \\
\hline Zhao et al ${ }^{19}$ & 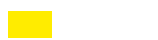 & 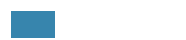 & 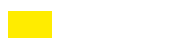 & 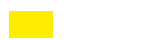 & 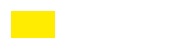 & 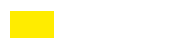 & $\square$ \\
\hline
\end{tabular}

Notes: _ low bias risk; _ , uncertain bias risk; _, high bias risk.

Study name

Barrett et al $(2013)^{13}$
Cheng et al $(2017)^{14}$
Luo et al $(2016)^{16}$
Zhang et al $(2006)^{18}$
Zhao et al $(2017)^{19}$
Total

Statistics for each study

Difference Lower Upper

in mean limit limit $p$-value
Difference in

mean and $95 \% \mathrm{Cl}$

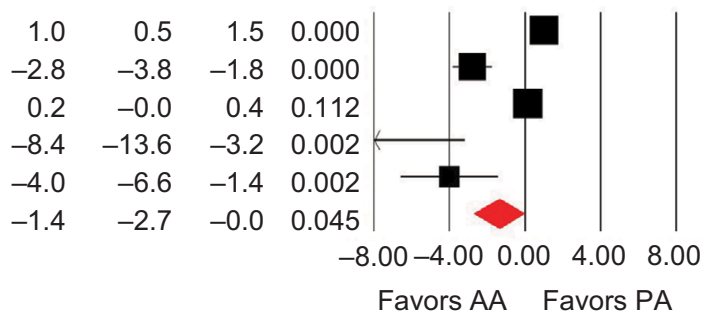

Figure 2 Incision length $(\mathrm{cm})$ with AA vs. PA in primary THA.

Notes: Difference in mean $<0$ favors AA and $>0$ favors PA. Heterogeneity: $P^{2}=94 \%, p<0.001$.

Abbreviations: AA, anterior approach; PA, posterior approach; THA, total hip arthroplasty.

among 4 studies (Figure 9). ${ }^{13,14,17,19}$ Significant heterogeneity among studies was observed for incision length, procedure time, operative blood loss, blood transfusions, and hospital stay but not for pain severity, opioid use, and complications (Table 3).

\section{Discussion}

The study reports a systematic review and meta-analysis of RCTs comparing the AA and PA in primary THA. Among 7 RCTs with 609 patients, hospital outcomes favoring the AA included shorter incision length, shorter hospital stay, 
Study name

Barrett et al $(2013)^{13}$

Cheng et al $(2017)^{14}$

Christensen and Jacobs $(2015)^{15}$

Zhang et al $(2006)^{18}$

Zhao et al $(2017)^{19}$

Total
Statistics for each study

Difference Lower Upper

in mean limit limit $p$-value

$\begin{array}{rrrr}-0.7 & -1.4 & -0.1 & 0.034 \\ -0.2 & -0.4 & 0.1 & 0.146 \\ -0.6 & -1.0 & -0.2 & 0.007 \\ -6.5 & -12.1 & -0.9 & 0.023 \\ -0.5 & -1.0 & -0.0 & 0.038 \\ -0.5 & -0.8 & -0.1 & 0.010\end{array}$

Difference in mean and $95 \% \mathrm{Cl}$

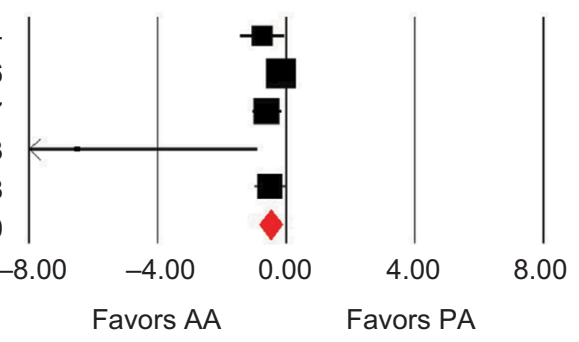

Figure 3 Hospital stay (days) with AA vs. PA in primary THA.

Notes: Difference in mean $<0$ favors AA and $>0$ favors PA. Heterogeneity: $P=59 \%, p=0.04$.

Abbreviations: AA, anterior approach; PA, posterior approach; THA, total hip arthroplasty.

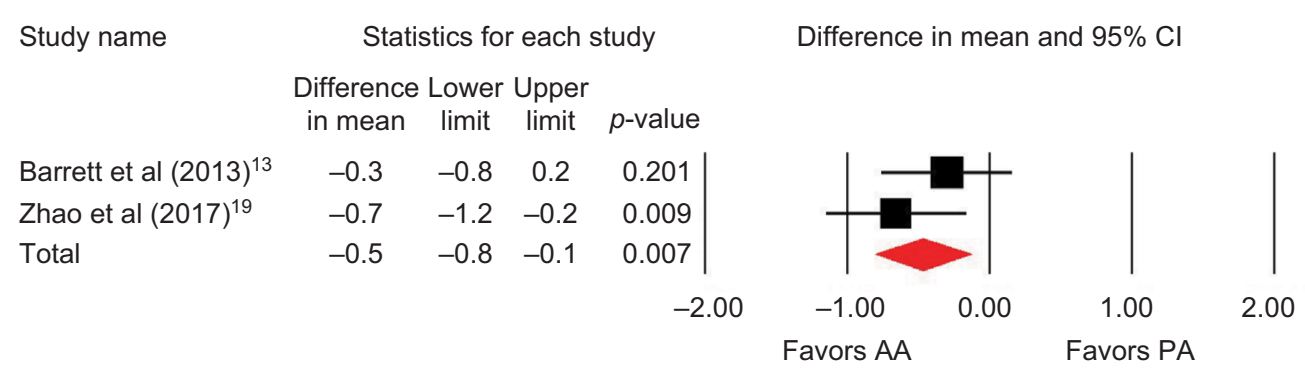

Figure 4 Postoperative pain (0-10 visual analog scale) with AA vs. PA in primary THA.

Notes: Difference in mean $<0$ favors $A A$ and $>0$ favors PA. Heterogeneity: $P=9 \%, p=0.30$.

Abbreviations: AA, anterior approach; PA, posterior approach; THA, total hip arthroplasty.

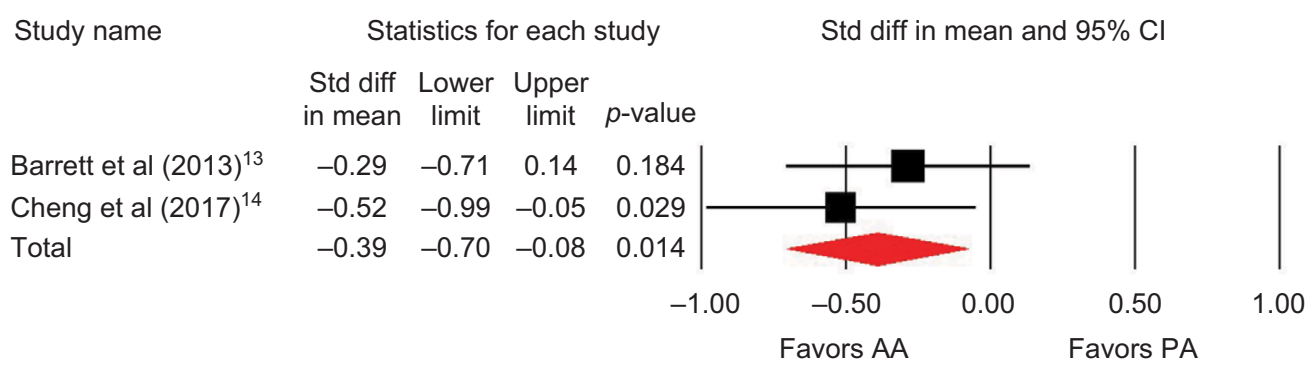

Figure 5 Opioid requirements with AA vs. PA in primary THA.

Notes: Standardized difference in mean $<0$ favors AA and $>0$ favors PA. Heterogeneity: $P^{2}=0 \%, p=0.47$.

Abbreviations: AA, anterior approach; PA, posterior approach; Std diff, standard difference; THA, total hip arthroplasty.

Study name
Barrett et al $(2013)^{13}$
Cheng et al $(2017)^{14}$
Luo et al $(2016)^{16}$
Zhang et al $(2006)^{18}$
Zhao et al $(2017)^{19}$
Total

Statistics for each study

Difference Lower Upper

in mean limit limit $p$-value

$\begin{array}{rrrr}24 & 19 & 29 & 0.000 \\ 25 & 17 & 33 & 0.000 \\ 3 & -0 & 7 & 0.064 \\ 6 & -11 & 23 & 0.499 \\ 18 & 14 & 22 & 0.000 \\ 16 & 6 & 25 & 0.002\end{array}$

$-30.00$

Favors AA
Difference in mean and $95 \% \mathrm{Cl}$

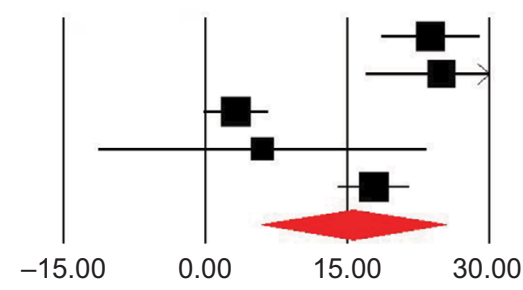

Favors PA

Figure 6 Procedure time (minutes) with AA vs. PA in primary THA.

Notes: Difference in mean $<0$ favors $A A$ and $>0$ favors PA. Heterogeneity: $P^{2}=94 \%, p<0.00$ I.

Abbreviations: AA, anterior approach; PA, posterior approach; THA, total hip arthroplasty 


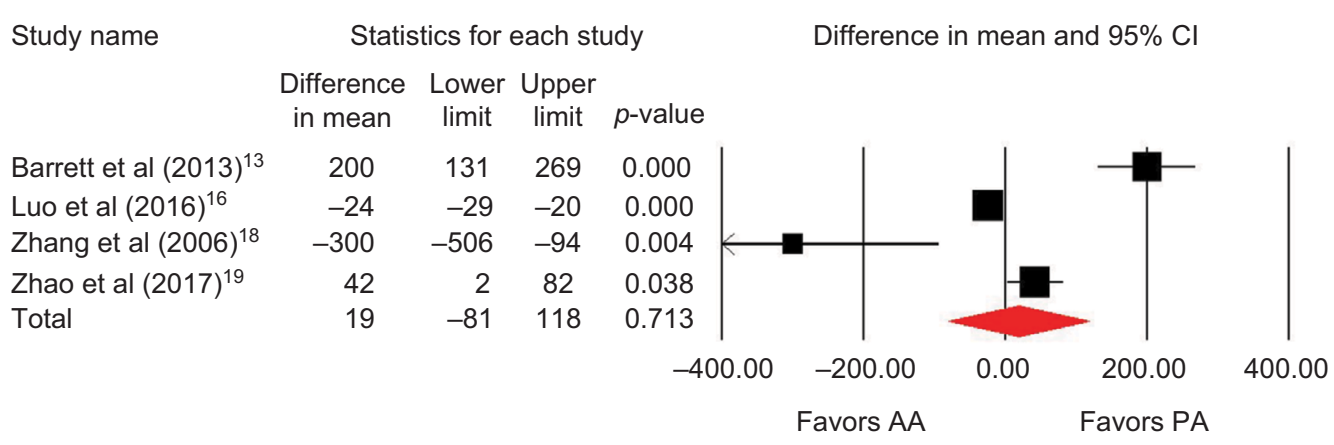

Figure 7 Estimated blood loss $(\mathrm{mL})$ with $A A$ vs. PA in primary THA.

Notes: Difference in mean $<0$ favors $A A$ and $>0$ favors PA. Heterogeneity: $P^{2}=95 \%, p<0.00 \mathrm{I}$.

Abbreviations: AA, anterior approach; PA, posterior approach; THA, total hip arthroplasty.

Study name
Cheng et al $(2017)^{14}$
Luo et al $(2016)^{16}$
Zhang et al $(2006)^{18}$
Zhao et al $(2017)^{19}$
Total

\begin{tabular}{|c|c|c|c|}
\hline \multicolumn{4}{|c|}{ Statistics for each study } \\
\hline & $\begin{array}{l}\text { Lower } \\
\text { limit }\end{array}$ & $\begin{array}{l}\text { Upper } \\
\text { limit }\end{array}$ & $p$-value \\
\hline .09 & 0.21 & 5.81 & 0.916 \\
\hline 31 & 0.06 & 1.60 & 0.160 \\
\hline 0.07 & 0.03 & 0.16 & 0.000 \\
\hline & 0.49 & 14.16 & 0.258 \\
\hline 45 & 0.08 & 2.72 & 0.387 \\
\hline
\end{tabular}

0.01

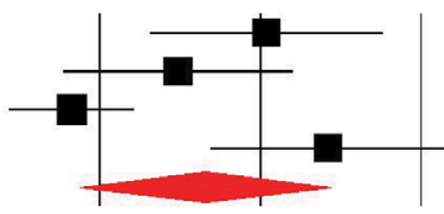

$10 \quad 100$
OR and $95 \% \mathrm{Cl}$

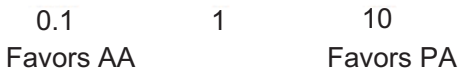

Figure 8 Need for transfusion with AA vs. PA in primary THA.

Notes: $O R<I$ favors $A A$ and $>I$ favors PA. Heterogeneity: $I^{2}=84 \%, p<0.00$ I.

Abbreviations: AA, anterior approach; PA, posterior approach; THA, total hip arthroplasty; OR, odds ratio.

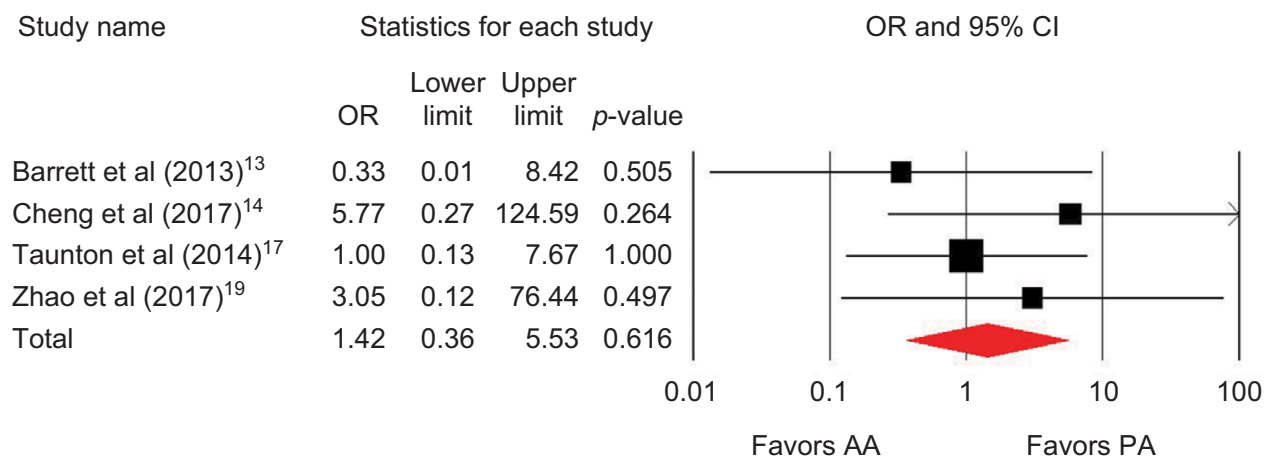

Figure 9 Hospital complications with AA vs. PA in primary THA.

Notes: $O R<I$ favors $A A$ and $>$ I favors PA. Heterogeneity: $I^{2}=0 \%, p=0.59$.

Abbreviations: AA, anterior approach; PA, posterior approach; THA, total hip arthroplasty; OR, odds ratio.

slightly less pain, and lower postoperative opioid use. The outcome in favor of the PA was shorter procedure time. No differences between surgical approaches were observed in operative blood loss, transfusion rate, or hospital complications. These data constitute Level I evidence and, to the authors' knowledge, represent the first direct-evidence meta-analysis of RCTs evaluating the influence of AA vs. PA on THA outcomes.
Comparisons between our findings and those from other meta-analyses with the AA for primary THA are warranted. The main distinguishing elements of the current meta-analysis were inclusion of only RCTs and a focus on hospital outcomes. In contrast, other meta-analyses have included nonrandomized studies or indirect evidence to develop conclusions. The meta-analysis of Higgins et $\mathrm{al}^{6}$ evaluating AA vs. PA reported that the AA was associated 
Table 3 Summary of hospital outcomes with AA vs. PA in primary THA

\begin{tabular}{|c|c|c|c|c|c|c|c|}
\hline \multirow[t]{2}{*}{ Outcome } & \multirow{2}{*}{$\begin{array}{l}\text { No. of } \\
\text { studies }\end{array}$} & \multirow{2}{*}{$\begin{array}{l}\text { Statistic, } \\
\text { model }\end{array}$} & \multicolumn{3}{|c|}{ Difference between approaches } & \multicolumn{2}{|c|}{ Heterogeneity } \\
\hline & & & Effect size & $95 \% \mathrm{Cl}$ & $p$-value & $I^{2}(\%)$ & $p$-value \\
\hline \multicolumn{8}{|l|}{ Favors AA } \\
\hline Incision length & 5 & WMD, random & $1.4 \mathrm{~cm}$ shorter with $\mathrm{AA}$ & -2.7 to $0 \mathrm{~cm}$ & 0.045 & 94 & $<0.001$ \\
\hline Hospital stay & 5 & WMD, random & 0.5 days shorter with $A A$ & -0.8 to -0.1 days & 0.01 & 59 & 0.04 \\
\hline Pain severity & 2 & WMD, fixed & 0.5 points lower with $A A$ & -0.8 to -0.1 points & 0.007 & 9 & 0.30 \\
\hline Opioid use & 2 & SMD, fixed & -0.39 , favoring $\mathrm{AA}^{\mathrm{a}}$ & -0.70 to -0.08 & 0.01 & 0 & 0.47 \\
\hline \multicolumn{8}{|l|}{ Favors PA } \\
\hline Procedure time & 5 & WMD, random & 16 min shorter with PA & 6-25 minutes & 0.002 & 94 & $<0.001$ \\
\hline \multicolumn{8}{|l|}{$\begin{array}{l}\text { Favors neither } \\
\text { approach }\end{array}$} \\
\hline Operative blood loss & 4 & WMD, random & $19 \mathrm{~mL}$ more with $\mathrm{AA}$ & $-8 \mathrm{I}$ to $118 \mathrm{~mL}$ & 0.71 & 95 & $<0.001$ \\
\hline Transfusion & 4 & OR, random & 0.45 , lower risk with $A A$ & $0.08-2.72$ & 0.39 & 84 & $<0.001$ \\
\hline Complication & 4 & OR, fixed & I.42, higher risk with $\mathrm{AA}$ & $0.36-5.53$ & 0.62 & 0 & 0.59 \\
\hline
\end{tabular}

Note: aSMD of -0.39 implies small-to-medium effect favoring AA.

Abbreviations: AA, anterior approach; OR, odds ratio; PA, posterior approach; SMD, standardized mean difference; THA, total hip arthroplasty; WMD, weighted mean difference.

with less pain, greater function, shorter hospital stays, and lower narcotic consumption but no difference in blood loss. Meermans et $\mathrm{al}^{7}$ reported greater early function, no difference in incision length, and longer procedure time with AA vs. PA. In a network meta-analysis of RCTs, Putananon et $\mathrm{al}^{21}$ used indirect evidence from a network meta-analysis to conclude that AA was associated with less postoperative pain and better hip function but higher complication rates vs. PA. Synthesis of evidence from all sources including the current review consistently suggests that outcomes with AA and PA are comparable, with key exceptions of longer procedure time, slightly less pain, lower narcotic use, and shorter hospital stay with AA.

While the findings of the current analysis represent results derived only from RCTs, considerable inconsistency was observed among studies for most outcomes. While data describing potential sources of heterogeneity among studies such as age, gender, and BMI were collected, there were an insufficient number of studies to formally evaluate these associations. Since patient characteristics among studies were generally similar, a more probable explanation for variability in outcomes was surgeon and institutional experience with the AA procedure. While not quantifiable in the current review, previous studies have reported that 50-100 AA cases are required to overcome a learning curve effect. ${ }^{22,23}$ The extent to which this learning curve was overcome among studies in this review is unclear. As more RCTs on the topic become available, sources of heterogeneity among studies may be able to be rigorously evaluated with subgroup analysis or meta-regression to potentially identify surgeon and patient factors that are associated with patient outcomes.
The strengths of this meta-analysis are inclusion of only RCTs and a comprehensive list of clinically relevant hospital outcomes. This meta-analysis is also associated with several limitations that may influence interpretation. First, despite certain advantages of the AA, patient outcomes beyond hospital discharge cannot be evaluated in this review. Nevertheless, the focus on the in-hospital timeframe remains a major component of perioperative recovery metrics. Second, results should be interpreted cautiously given the small number of available studies, significant heterogeneity for many outcomes, and uncertain bias risk for attributes of many study designs. Third, it was not possible to consistently extract hospital complication data for this review. The majority of included RCTs reported complication incidence through final follow-up, and detailed accounting of specific complications was generally insufficient. Therefore, the reliability of the complication data reported in the current study is unclear. In studies where hospital complication data were available, no statistical differences in complication rates were observed. Future RCTs comparing surgical approaches with primary THA should consider more comprehensive reporting that details the time course and seriousness of reported complications.

\section{Conclusion}

In this first systematic review and direct-evidence metaanalysis of RCTs comparing AA with PA in primary THA, the AA was associated with shorter incision length, shorter hospital stays, less pain, and lower postoperative opioid use but longer procedure time. The clinical relevance of these differences during longer-term follow-up is uncertain. No 
differences were noted for operative blood loss, blood transfusions, or hospital complications. The choice of surgical approach in primary THA should also consider factors such as experience of the surgeon and preferences of the surgeon and patient.

\section{Acknowledgments}

The authors thank David Fay, PhD, for assistance with literature review. The institution of one or more authors (LEM, AFK, and FB) has received funding from DePuy Synthes.

\section{Disclosure}

SKB is an employee of DePuy Synthes. The authors report no other conflicts of interest in this work.

\section{References}

1. Moss AS, Murphy LB, Helmick CG, et al. Annual incidence rates of hip symptoms and three hip OA outcomes from a U.S. population-based cohort study: the Johnston County Osteoarthritis Project. Osteoarthritis Cartilage. 2016;24(9):1518-1527.

2. Daigle ME, Weinstein AM, Katz JN, Losina E. The cost-effectiveness of total joint arthroplasty: a systematic review of published literature. Best Pract Res Clin Rheumatol. 2012;26(5):649-658.

3. Kurtz S, Ong K, Lau E, Mowat F, Halpern M. Projections of primary and revision hip and knee arthroplasty in the United States from 2005 to 2030. J Bone Joint Surg Am. 2007;89(4):780-785.

4. den Hartog YM, Mathijssen NM, Vehmeijer SB. The less invasive anterior approach for total hip arthroplasty: a comparison to other approaches and an evaluation of the learning curve - a systematic review. Hip Int. 2016;26(2):105-120.

5. Poehling-Monaghan KL, Kamath AF, Taunton MJ, Pagnano MW. Direct anterior versus miniposterior THA with the same advanced perioperative protocols: surprising early clinical results. Clin Orthop Relat Res. 2015;473(2):623-631.

6. Higgins BT, Barlow DR, Heagerty NE, Lin TJ. Anterior vs. posterior approach for total hip arthroplasty, a systematic review and metaanalysis. J Arthroplasty. 2015;30(3):419-434.

7. Meermans G, Konan S, Das R, Volpin A, Haddad FS. The direct anterior approach in total hip arthroplasty: a systematic review of the literature. Bone Joint J. 2017;99-B(6):732-740.

8. Yue C, Kang P, Pei F. Comparison of direct anterior and lateral approaches in total hip arthroplasty: a systematic review and metaanalysis (PRISMA). Medicine (Baltimore). 2015;94(50):e2126.
9. Liberati A, Altman DG, Tetzlaff J, et al. The PRISMA statement for reporting systematic reviews and meta-analyses of studies that evaluate health care interventions: explanation and elaboration. Ann Intern Med. 2009;151:W65-W94.

10. Higgins JP, Altman DG, Gotzsche PC, et al; Cochrane Bias Methods Group; Cochrane Statistical Methods Group. The Cochrane Collaboration's tool for assessing risk of bias in randomised trials. $B M J$. 2011;343:d5928.

11. Cohen J. Statistical Power Analysis for the Behavioral Sciences. Hillside, NJ: Lawrence Erlbaum Associates; 1987.

12. Higgins JP, Thompson SG, Deeks JJ, Altman DG. Measuring inconsistency in meta-analyses. BMJ. 2003;327(7414):557-560.

13. Barrett WP, Turner SE, Leopold JP. Prospective randomized study of direct anterior vs postero-lateral approach for total hip arthroplasty. J Arthroplasty. 2013;28(9):1634-1638.

14. Cheng TE, Wallis JA, Taylor NF, et al. A prospective randomized clinical trial in total hip arthroplasty-comparing early results between the direct anterior approach and the posterior approach. $J$ Arthroplasty. 2017;32(3):883-890.

15. Christensen CP, Jacobs CA. Comparison of patient function during the first six weeks after direct anterior or posterior Total Hip Arthroplasty (THA): a randomized study. J Arthroplasty. 2015;30(9 suppl):94-97.

16. Luo Z, Chen M, Shangxi F, et al. [Comparison of clinical efficacy of total hip arthroplasty and lateral posterior approach for total hip arthroplasty]. Chin J Med Sci. 2016;96:2807-2812. Chinese.

17. Taunton MJ, Mason JB, Odum SM, Springer BD. Direct anterior total hip arthroplasty yields more rapid voluntary cessation of all walking aids: a prospective, randomized clinical trial. J Arthroplasty. 2014;29(9 suppl):169-172.

18. Zhang XL, Wang Q, Jiang Y, Zeng BF. [Minimally invasive total hip arthroplasty with anterior incision]. Zhonghua Wai Ke Za Zhi. 2006;44(8):512-515. Chinese.

19. Zhao HY, Kang PD, Xia YY, Shi XJ, Nie Y, Pei FX. Comparison of early functional recovery after total hip arthroplasty using a direct anterior or posterolateral approach: a randomized controlled trial. J Arthroplasty. 2017;32(11):3421-3428.

20. Reininga IH, Stevens M, Wagenmakers R, et al. Comparison of gait in patients following a computer-navigated minimally invasive anterior approach and a conventional posterolateral approach for total hip arthroplasty: a randomized controlled trial. J Orthop Res. 2013;31(2):288-294.

21. Putananon C, Tuchinda H, Arirachakaran A, Wongsak S, Narinsorasak T, Kongtharvonskul J. Comparison of direct anterior, lateral, posterior and posterior-2 approaches in total hip arthroplasty: network meta-analysis. Eur J Orthop Surg Traumatol. 2017;28(2):255-267.

22. de Steiger RN, Lorimer M, Solomon M. What is the learning curve for the anterior approach for total hip arthroplasty? Clin Orthop Relat Res. 2015;473(12):3860-3866.

23. Hartford JM, Bellino MJ. The learning curve for the direct anterior approach for total hip arthroplasty: a single surgeon's first 500 cases. Hip Int. 2017;27(5):483-488.
Journal of Pain Research

\section{Publish your work in this journal}

The Journal of Pain Research is an international, peer reviewed, open access, online journal that welcomes laboratory and clinical findings in the fields of pain research and the prevention and management of pain. Original research, reviews, symposium reports, hypothesis formation and commentaries are all considered for publication.

\section{Dovepress}

The manuscript management system is completely online and includes a very quick and fair peer-review system, which is all easy to use. Visit http://www.dovepress.com/testimonials.php to read real quotes from published authors. 